\title{
Singapore's response to the severe acute respiratory syndrome outbreak: what do Singapore physicians think?
}

\author{
Feng Qian • Meng Kin Lim
}

Received: 14 July 2009/Revised: 2 November 2009/Accepted: 15 November 2009/Published online: 4 December 2009

(c) Birkhäuser Verlag, Basel/Switzerland 2009

\begin{abstract}
Objective To gauge Singapore physicians' perceptions of the national response to the severe acute respiratory syndrome (SARS) outbreak using a questionnaire survey. Methods Random sampling was applied to draw the survey population. Descriptive analysis and logistic regressions were used.

Results The majority of physicians agreed that home quarantine of contacts of patients with probable SARS was warranted $(95 \%)$, government's public education effort was effective (83\%), and the overall Singapore's response was commendable (82\%). Only $38 \%$, however, agreed that health care workers were supplied with timely and adequate personal protective equipment.

Conclusions Most Singapore physicians have positive comments about the national response to the SARS crisis. However, systematic weaknesses are identified and recommendations are presented.
\end{abstract}

Keywords Physicians - Survey ·

Severe acute respiratory syndrome $\cdot$ Singapore

\section{F. Qian $(\bowtie)$}

Department of Community and Preventive Medicine,

School of Medicine \& Dentistry, University of Rochester,

601 Elmwood Avenue, Box 644, Rochester, NY 14642, USA

e-mail: feng_qian@urmc.rochester.edu

\section{K. Lim}

Department of Epidemiology and Public Health,

Yong Loo Lin School of Medicine,

National University of Singapore, Singapore, Singapore

e-mail: ephlmk@nus.edu.sg

\section{Introduction}

In 2003, Singapore faced a test with the outbreak of severe acute respiratory syndrome (SARS). Parliament hastily passed an amendment to the existing Infectious Diseases Bill to strengthen the government's powers to deal with the crisis (Quah and Lee 2004). People were jailed for breaking Home Quarantine Orders. The economy took a terrible turn and many businesses folded. As researchers raced against time to find a vaccine or cure, heart-wrenching and inspirational stories of courage and selflessness emerged as physicians and nurses risked their lives to save patients from this previously unknown infectious disease. Five health care workers (HCWs) lost their precious lives, along with 28 ordinary citizens.

Although the SARS threat was over by mid-2003, it was very important to reflect on Singapore's response to the SARS outbreak Singapore's adoption of a "wide-net" approach to surveillance and isolation of suspected cases was effective, although some have also pointed out that its seemingly draconian quarantine measures might not be suitable for other countries (Teo et al. 2005).

At the beginning of the SARS outbreak, some HCWs had lost their lives while some HCWs refused to look after SARS patients or even resigned. HCWs were perceived as a potential and dangerous source of infection in the community due to their contact with SARS patients. Later, however, when the public was better informed and educated, they gave the frontline HCWs great support and even honored HCWs as heroes (Tai 2006). Understanding the fears and anxieties of HCWs at the frontline during SARS may be informative and useful for handling future outbreaks of a similar nature (Leung et al. 2004). Koh et al. found that candid acknowledgment of the risks and timely implementation of simple protective measures could avoid 
panic among HCWs (Koh et al. 2005). Chia et al. found that a variety of factors, such as job title, reported contact with SARS patients, area of work, and Impact Events Scale scores might help to determine appropriate use of personal protective equipment (PPE) by HCWs (Chia et al. 2005).

But, none of the above studies focused on physicians' perception of the overall Singapore's response to SARS. Given that physicians play important and irreplaceable roles in the healthcare system, their perspectives would be helpful in identifying the weak links in the strategies employed in the battle, leading to adjustments that will enhance preparations for the next war. We therefore, conducted a questionnaire survey to find out what Singapore physicians thought of Singapore's response to the SARS outbreak.

\section{Methods}

The sampling frame comprised all physicians in the public and private sectors as listed in the Singapore Physicians Directory (2001/2002), stratified into two categories: general practitioners (GPs) and specialists. The study was limited to five clinical specialties, namely: anesthesiologists, cardiologists, gastroenterologists, general surgeons, and obstetrician and gynecologists, while the GPs were confined to those in clinical practice in the private sector-thus excluding GPs in the public sector, many of whom are actually in administrative positions. Random sampling yielded 633 GPs in the private sector, 329 specialists in the private sector, and 288 specialists in the public sector.

The questionnaire comprised 2 sections. Section 1 measures physicians' perception of Singapore's response to the SARS outbreak, while Section 2 measures the demographic profiles of the physicians. A 5-point Likert scale is used for Section 1, with responses "strongly disagree", "disagree", "neutral", "agree" and "strongly agree", and "NA" for "not applicable". The questionnaire was mailed together with prepaid, self-addressed envelopes, to be self-administered as the respondents were well-educated, and would probably prefer to complete the questionnaire at their own convenience. Anonymity and confidentiality of respondents were ensured. The timing of the physicians' survey in is listed as below: November 17-December 16, 2003 for the first wave mailing, December 17-January 16, 2004 for the second wave mailing, and January 17-January 20, 2004 for the final telephone reminder. All returned questionnaires were checked manually for completeness before they were forwarded for electronic data capture. Data analysis involved descriptive stratification and multiple logistic analysis using SPSS version 16.0 (2008, SPSS Inc of Chicago, Illinois).

\section{Results}

As much as 380 valid questionnaires were returned with a response rate of $30.4 \%$. The demographic characteristics of the respondents are listed in Table 1 . The majority of physicians agreed that "home quarantine was warranted" (95\%), "public education was effective" (83\%), "overall response was commendable" (82\%), "HCWs accepted job risk of SARS" (81\%), "it was HCWs' duty to treat SARS patients" (76\%), "healthcare system was unprepared for the SARS outbreak" (71\%), "quarantine of HCWs was warranted" (71\%), "information flow was open and transparent" (71\%), "public health officials performed well" (63\%), "political leaders handled the situation competently" (63\%), "public health policy was commendable" (61\%), "unprotected HCWs might resign" (58) while only a small portion of physicians agreed that "HCWs were supplied timely and adequate PPE" (38\%), and "healthcare system remains unprepared for the next outbreak" (16\%). Female physicians $(94 \%)$ were more likely to agree that "political leaders handled the situation competently" than male physicians $(82 \%, p=0.01)$. Specialists $(56 \%)$ were more likely to agree that "HCWs were supplied timely and adequate PPE" than GPs $(39 \%, p=0.01)$.

Physicians with different years of working experience differed in their responses to the following items: "quarantine of HCWs was warranted" $(p=0.004)$; "HCWs were supplied timely and adequate $\operatorname{PPE} "(p=0.03)$. Physicians with 10-19 working years, 20-29 working years, and over 30 working years were more likely $(82,84$, and $83 \%$, respectively) to agree that "quarantine of HCWs was warranted" than physicians with 5-9 working years (63\%), and were more likely (44, 50, and 58\%, respectively) to agree that "HCWs were supplied timely and adequate PPE" than physicians with 5-9 working years (19\%).

Multiple logistic regression is applied to find the factors influencing physicians' perceptions toward "HCWs were supplied timely and adequate PPE". All the potential predictors who entered the final model were selected by univariate analysis at the significance level of $p=0.20$. The final model was created by using stepwise technique. The variables in the final models were: gender, working years, age, private/public, and annual income. We arbitrarily set the reference group as: male, 5-9 working years, 30-39 years, specialist, working in the private sector, annual income less than US $\$ 30,000$. Table 2 shows that responses that differed significantly between specialists and GPs (OR $0.47,95 \%$ CI $0.26-0.85$ ). 
Table 1 Socio-demographic characteristics of the respondents

\begin{tabular}{lll}
\hline Characteristics & $\begin{array}{l}\text { Number of } \\
\text { respondents }\end{array}$ & $\begin{array}{l}\text { Percentage of } \\
\text { respondents (\%) }\end{array}$ \\
\hline
\end{tabular}

\section{Gender}

Male

Female

269

111

70.8

Working years

$<5$ years

5-9 years

10-19 years

20-29 years

30 years or more

Age

$<30$ years

30-39 years

40-49 years

50-59 years

60 years or more

Nature of practice

Private clinic (solo)

Private group practice

Public primary care clinic

Public specialist clinic

Private hospital

Public hospital

Others

Missing values ${ }^{\mathrm{b}}$

Specialists/GPs

Specialists

GPs

Missing values ${ }^{\mathrm{b}}$

Annual income

$<$ US $\$ 30,000$

US $\$ 30,000-59,999$

US $\$ 60,000-99,999$

US $\$ 100,000-199,999$

US $\$ 200,000-299,999$

More than US $\$ 300,000$

$\begin{array}{rl}0 & 0.0 \\ 17 & 4.5 \\ 146 & 38.4 \\ 141 & 37.1 \\ 76 & 20.0\end{array}$

Table 2 Logistic regression for factors associated with "agree" or "strongly agree" to "HCWs were supplied timely and adequate PPE" $(n=292)$

\begin{tabular}{ll}
\hline Variables & OR $(95 \%$ CI $)$ \\
\hline Gender & \\
Male & 1 \\
Female & $1.26(0.73,2.18)$ \\
Working years & \\
5-9 years & 1 \\
10-19 years & $2.63(0.66,10.47)$ \\
20-29 years & $2.71(0.59,12.47)$ \\
30 years or more & $2.19(0.38,12.63)$ \\
Age & \\
30-39 years & 1 \\
40-49 years & $1.31(0.59,2.89)$ \\
50-59 years & $1.54(0.53,4.45)$ \\
60 years or more & $3.77(0.90,15.78)$ \\
Specialists/GPs & \\
Specialists & 1 \\
GPs & $0.47 *(0.26,0.85)$ \\
Annual income & \\
$<$ US $\$ 30,000$ & 1 \\
US \$30,000-59,999 & $1.16(0.38,3.50)$ \\
US \$60,000-99,999 & $1.50(0.53,4.29)$ \\
US \$100,000-199,999 & $1.06(0.37,3.07)$ \\
US $\$ 200,000-299,999$ & $0.97(0.29,3.26)$ \\
$\geq$ US $\$ 300,000$ & $0.73(0.19,2.83)$ \\
\hline
\end{tabular}

$* p<0.05$

system. As the literature suggests that physicians experienced psychological morbidity, such as anxiety and distress during the SARS war in Canada, Hong Kong, Singapore, and Taiwan (Avendano et al. 2003; Leung et al. 2003; Maunder et al. 2003; Koh et al. 2005), it might lead physicians to experience less personal worry and perceived vulnerability to the unknown disease when they place a high level of trust in the health care system to manage future epidemics (Deurenberg-Yap et al. 2005).

Most of the physicians had positive attitudes toward the ${ }^{a}$ No responses were received from physicians $<30$ years old or within 5 working years because in Singapore, all medical graduates are bonded to serve the government for a period of 5 years- which is insufficient time to either specialize or start private practice as a GP

b The reason for above missing values is that respondents did not fill the corresponding fields

\section{Discussion}

Our survey reveals the good morale of Singapore physicians as a group when they were challenged by the unprecedented killer disease. This shows the strong confidence of Singapore physicians on the current healthcare

Singapore's overall response, public education, and information flow. This is consistent with the findings from other studies which focus on the perception of ordinary citizens (Leung et al. 2003; Quah and Lee 2004; Deurenberg-Yap et al. 2005). The timely provision of updated information on SARS is very important given that there is a lot of information and misinformation on SARS circulating in the communities. Good and transparent communications can help to build mutual respect and nurture public trust and confidence in getting over the crisis (Menon 2006). In contrast, poor communication could lead to doubt, mistrust, and even panic. Hong Kong physicians complained that the 
government acted relatively slowly and weakly at the beginning of the SARS crisis (Ma 2004). In China, poor communications affected political stability (China sacked her health minister and Beijing's mayor) and gave rise to high levels of public unhappiness (Ashraf 2003).

One of the debated issues is quarantine, which involves the separation and/or restriction of movement of persons who are not ill, but suspected to be carrying an infection due to recent exposure. In our study, almost all physicians agreed with using home quarantine in fighting against SARS. Previous study shows that the majority of Singaporeans gave positive assessments and complied well with home quarantine (Ooi and Lim 2005). As Bell pointed out that quarantine is one of a science-based intervention that aims to separate persons potentially exposed to an infection from the general population (Bell 2004), the use of quarantine in Singapore helped the public to establish confidence to continue with their normal daily life. Singapore's experience underscored the importance of being prepared to use extraordinary measures to respond to epidemics. However, our findings have identified that the weakest part of the Singapore's preparedness to fight a future infectious diseases war is how to assure that HCWs are supplied timely and adequate PPE which is very critical in fighting against an unknown infectious disease epidemic. It reminds policy makers to pay sufficient attention to details like the timely provision of PPE to HCWs, including GPs. There were delays in getting PPE to GPs' clinics in the initial allocation of masks, gloves, and gowns. GPs act as forefront fighters as much as specialists in the hospitals. It is found that GPs persisted in using PPE and change their behavior to reduce the perceived threat to their own lives (Tan et al. 2006). One lesson we should learn is that private GP clinics play a critical role in communitybased responses to infectious disease outbreaks, and should be included early in any response plan. There are several limitations to our study. First, the response rate of $30.4 \%$ is rather low compared to studies in other developed countries (which typically range from $40 \%$ to $50 \%$ ) although it is comparable to other similar questionnaire surveys among physicians in Singapore (Committee 2003; Fung and Chow 1998). This may be due to differences in the culture of cooperation and disclosure, and hence may affect the generalizability. Second, our methodology limits the GPs to the private sector and specialists to only five categories, hence, our finding may not be representative of the entire physician population in Singapore. But, GPs in the public sector only comprise a very small portion of GPs in Singapore and they usually take on administrative roles. Thirdly, any international comparisons of physicians' views on SARS response must be interpreted in the light of differences between the health care system, political system, and social norms.

\section{Conclusion and recommendation}

Singapore's relative success in responding to the SARS crisis could be attributable to swift and decisive actions by the government, its small and manageable size, its generally law-abiding and compliant population, and its highlytrained medical workforce. A better understanding of physicians' perspectives would be increasingly important in dealing with future infectious disease outbreaks. The healthcare system and the general population will benefit greatly from the improved performance of the physicians. So, it is recommended that physicians' perspectives should be gauged and evaluated before designing major health policies. By doing so, policy makers could not only collect important information on a specific topic from a group of key players in the healthcare system but also help to form a benign cycle of mutual respect and trust with physicians in the process of policy making. Furthermore, the most important lessons learnt from this study are the need to pay greater attention to the timely provision of adequate PPE for all physicians, and the importance of involving the frontline GPs and private clinics in the national response. To address these issues, a more effective resource mobilization plan and a more comprehensive emergency response plan are needed. As a chain is only as strong as its weakest link, whether a national healthcare system can win the future battles against infectious disease epidemics or not could depend on some seemingly unimportant links. So, to identify the weakest links in the healthcare system and to find the solutions should be the imminent tasks for policy makers.

Conflict of interest statement There is no conflict of interest and no funding to disclose.

\section{References}

Ashraf H (2003) China finally throws full weight behind efforts to contain SARS. Lancet 361(9367): 1439

Avendano M, Derkach P et al (2003) Clinical course and management of SARS in health care workers in Toronto: a case series. CMAJ 168(13):1649-1660

Bell DM (2004) Public health interventions and SARS spread, 2003. Emerg Infect Dis 10(11):1900-1906

Chia SE, Koh D et al (2005) Appropriate use of personal protective equipment among healthcare workers in public sector hospitals and primary healthcare polyclinics during the SARS outbreak in Singapore. Occup Environ Med 62(7):473-477

Committee SMA (2003) Singapore Medical Association managed care survey. Singapore Med J 35(8):2-3

Deurenberg-Yap M, Foo LL et al (2005) The Singaporean response to the SARS outbreak: knowledge sufficiency versus public trust. Health Promot Int 20(4):320-326

Fung D, Chow M (1998) Doctors' and lawyers' perspectives of child abuse and neglect in Singapore. Singapore Med J 39(4):160-165 
Koh D, Lim MK et al (2005) Risk perception and impact of Severe Acute Respiratory Syndrome (SARS) on work and personal lives of healthcare workers in Singapore: what can we learn? Med Care 43(7):676-682

Leung GM, Lam TH et al (2003) The impact of community psychological responses on outbreak control for severe acute respiratory syndrome in Hong Kong. J Epidemiol Community Health 57(11):857-863

Leung GM, Quah S et al (2004) A tale of two cities: community psychobehavioral surveillance and related impact on outbreak control in Hong Kong and Singapore during the severe acute respiratory syndrome epidemic. Infect Control Hosp Epidemiol 25(12):1033-1041

Ma N (2004) SARS and the limits of the Hong Kong SAR administrative state. Asian Perspect 28(1):99-120

Maunder R, Hunter J et al (2003) The immediate psychological and occupational impact of the 2003 SARS outbreak in a teaching hospital. CMAJ 168(10):1245-1251
Menon KU (2006) SARS revisited: managing "outbreaks" with "communications. Ann Acad Med Singapore 35(5):361-367

Ooi PL, Lim S (2005) Use of quarantine in the control of SARS in Singapore. Am J Infect Control 33(5):252-257

Quah SR, Lee HP (2004) Crisis prevention and management during SARS outbreak, Singapore. Emerg Infect Dis 10(2):364-368

Tai DY (2006) SARS plague: duty of care of medical heroism? Ann Acad Med Singapore 35(5):374-378

Tan CC (2006) SARS in Singapore-key lessons from an epidemic. Ann Acad Med Singapore 35(5):345-349

Tan NC, Goh LG et al (2006) Family physicians' experiences, behaviour, and use of personal protection equipment during the SARS outbreak in Singapore: do they fit the Becker Health Belief Model? Asia Pac J Public Health 18(3):49-56

Teo P, Yeoh BS et al (2005) SARS in Singapore: surveillance strategies in a globalising city. Health Policy 72(3):279-291 